\title{
Desain Untuk Disabilitas \\ Perancangan Meja DAYA Untuk Mengakomodir Kebutuhan Mahasiswa Penyandang Tuna Daksa Pengguna Kursi Roda
}

\author{
Fitorio Bowo Leksono ${ }^{1}$, Hari Nugraha ${ }^{2}$, Donna Angelina ${ }^{3}$, Ismail Alif Siregar ${ }^{4}$ \\ ${ }^{1}$ Program Studi Desain Produk, Universitas Pembangunan Jaya \\ Tangerang Selatan, Banten 15413, Indonesia \\ ${ }^{2}$ Program Studi Desain Produk, Universitas Pembangunan Jaya \\ ${ }^{3}$ Program Studi Desain Produk, Universitas Pembangunan Jaya \\ ${ }^{4}$ Program Studi Desain Produk, Universitas Pembangunan Jaya \\ Email korespondensi: fitorio.leksono@upj.ac.id
}

Received 20 December 2020, Revised 24 March 2021, Accepted 10 May 2021

\begin{abstract}
The provision of education that provides opportunities for all students regardless of limitations has been guaranteed by law. Unfortunately, adequate facilities for students with special needs such as wheelchair users in many Higher Institutions are still insufficient, especially in classrooms. This article is a summary of research activities and the design process of the DAYA table that accommodates the needs of wheelchair users in the classroom. The DAYA desk is designed with the Design Thinking methodology, that further elaborate on empathy studies so that the need s of the user are accommodated, so that they can be more independent in following the course of lectures. The design of the DAYA table proves that in designing a product for people with disabilities, ergonomics studies are not enough, because they have to consider the habits and needs of users through empathy studies. These two things are often left untouched by ergonomic studies that focus more on physical parameters alone.
\end{abstract}

Keywords: Design Thinking, Disability, Empathic Study

\begin{abstract}
Abstrak - Penyelenggaraan pendidikan yang memberikan kesempatan bagi semua peserta didik terlepas dari keterbatasannya telah dijamin oleh Undang-Undang. Sayangnya fasilitas yang memadai bagi mahasiswa berkebutuhan khusus (disabilitas) seperti pengguna kursi roda di berbagai perguruan tinggi masih belum mencukupi, terutama di ruang kelas. Artikel ini merupakan rangkuman kegiatan penelitian dan proses desain dari produk meja (meja DAYA) yang dapat mengakomodasi kebutuhan peserta didik pengguna kursi roda di dalam kelas. Meja DAYA didesain dengan metodologi Design Thinking dengan lebih mengelaborasikan studi empati agar kebutuhan mahasiswa tersebut dapat terakomodasi. Hasil dari penelitian ini dapat membantu mahasiswa disabilitas agar dapat lebih mandiri dalam mengikuti jalannya perkuliahan. Desain dari meja DAYA membuktikan bahwa dalam mendesain sebuah produk untuk kaum disabilitas, studi ergonomi saja tidaklah cukup, karena harus mempertimbangkan kebiasaan dan kebutuhan dari pengguna melalui studi empati. Kedua hal ini sering kali tidak tersentuh oleh studi ergonomi yang lebih fokus pada parameter fisik semata.
\end{abstract}

Kata Kunci: Design Thinking, Disabilitas, Studi Empati

\section{PENDAHULUAN}

Pemanfaatan teori ergonomi untuk pembuatan fasilitas kampus khususnya untuk mahasiswa disabilitas pengguna kursi roda (tunadaksa) masih sangat jarang dilakukan oleh perguruan tinggi di Indonesia. Aksesibilitas yang optimal dapat mendorong kemandirian bagi penyandang disabilitas dalam beraktifitas secara normal (Syafi'ie, 2014).

Disabilitas dapat diartikan sebagai cacat tubuh sementara atau permanen yang menyebabkan hambatan atau kesulitan dalam melakukan aktifiktas atau fungsi fisik secara optimal (WHO, 2011). Sedangkan berdasarkan pada Permendiknas nomor
70 tahun 2009; Sistem penyelenggaraan pendidikan yang memberikan kesempatan kepada semua peserta didik yang memiliki kelainan dan memiliki potensi kecerdasan dan/atau bakat istimewa untuk mengikuti pendidikan atau pembelajaran dalam lingkungan pendidikan secara bersama-sama dengan peserta didik pada umumnya.

Fasilitas yang dapat disediakan yaitu dapat berupa penerapan aksesibilitas dan fasilitas penunjang (Lutfiyah et al., 2020). Umumnya fasilitas fisik dan penunjang lainnya belum memenuhi standar fungsi untuk dapat digunakan oleh penyandang disabilitas (Imrie, 2000). 
Saat ini, masih banyaknya perguruan tinggi yang belum menerapkan atau menyediakan fasilitas untuk para mahasiswa penyandang disabilitas, hal tersebut menjadi permasalahan tersendiri. Universitas Pembangunan Jaya sebagai sebuah institusi perguruan tinggi yang baru berdiri selama delapan tahun dan tergolong baru, mempunyai komitmen menjadi perguruan tinggi yang memberikan akses dan fasilitas kepada mahasiswa menyandang disabilitas sehingga mereka bisa mengikuti pembelajaran selaiknya mahasiswa tanpa kebutuhan khusus.

\section{TINJAUAN LITERATUR}

Penggunaan teori ergonomi, lebih banyak diterapkan pada produk pakai untuk pengguna dengan kebutuhan normal. Sedangkan para mahasiswa yang berkebutuhan khusus mempunyai standar-standar ergonomi yang berbeda dan desain yang dibuat harus disesuaikan dengan kebutuhan penggunanya (Shinohara, K et al. 2016). Standar ergonomi inilah yang akan menjadi acuan dalam pembuatan desain fasilitas penunjang kegiatan belajar mahasiswa tersebut. Studi kasus pada penelitian ini, dilakukan di Universitas Pembangunan Jaya (UPJ). Selain itu, diharapkan hasil studi dan pembuatan purwarupa yang dihasilkan dari penelitian ini dapat menjadi acuan untuk perguruan tinggi dan institusi pendidikan lainnya dalam menciptakan kegiatan belajar mengajar yang kondusif melalui penyediaan fasilitas yang dapat menunjang aktivitas perkuliahan mahasiswa disabilitas. Penelitian terdahulu yang dilakukan untuk menyelesaikan permasalahan ergonomi ditinjau dari aspek antropometri penggunanya telah dilakukan oleh Wignjosoebroto (2007), penelitian tersebut fokus untuk melakukan redesain dimensi dari struktur rangka kursi yang dibuat dengan cara konvensional oleh UKM. Penelitian tersebut belum membahas mengenai redesain alat kerja lainnya seperti meja yang mempertimbangkan aspek ergonomi terutama untuk faktor yang berkaitan langsung dengan pengguna disabilitas atau penyandang tunadaksa. Penelitian tersebut menguraikan aspek antropometri dan ergonomi dari desain kursi yang mengikuti bentuk kontur organik dan bentuk anatomi atau postur dari penggunanya, Prototype kursi yang dihasilkan dari penelitian tersebut masih berupa rancangan untuk pengguna normal. Selain itu, berdasarkan Anoraga (1998) prinsip-prinsip ergonomi dapat meningkatkan produktivitas kerja. Dengan meningkatnya produktivitas diharapkan kegiatan pembelajaran dan kegiatan mahasiswa disabilitas di kampus dapat merasa lebih nyaman selayaknya kolega mereka yang tidak menyandang disabilitas.

\section{METODOLOGI}

Proses pengembangan model teknologi bantu ini menggunakan metodologi Design Thinking (DT) dari D School Stanford University (Gambar 1). Metodologi ini banyak digunakan oleh praktisi desain untuk memecahkan permasalahan yang ada. Metodologi ini terdiri dari 5 tahap, yaitu: (1) Empathize, (2) Define, (3) Ideation, (4) Prototyping, (5) Evaluate.

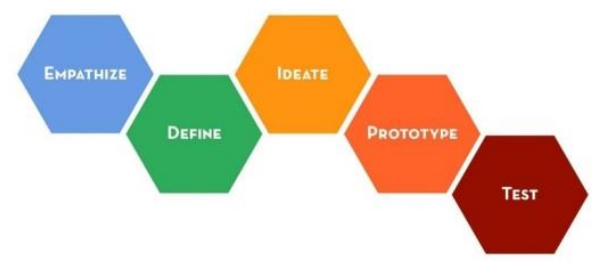

Gambar 1. Metodologi Design Thinking

Sebagaimana yang bisa dilihat di Gambar 1, tahapan Design Thinking yaitu; (1) Empathize, tahapan ini di mana desainer harus memahami kebutuhan dan perspektif pengguna. Proses tersebut dilakukan dalam bentuk wawancara langsung terhadap objek penelitian yaitu mahasiswa disabilitas. (2) Define, ini adalah tahap di mana ditentukannya batasan masalah yang didapat dari hasil analisa wawancara. (3) Ideation, di sini adalah tahap di mana dilakukan proses pencarian ide untuk mendapatkan solusi dari permasalahan yang telah didefinisikan pada tahapan sebelumnya. Teknik sketsa digunakan untuk pencarian ide. (4) Prototyping, di sini adalah tahap di mana hasil sketsa yang telah dipilih diwujudkan dalam bentuk 3 dimensi dengan skala 1:1. Studi dimensi ini nantinya akan diwujudkan menjadi produk jadi atau purwarupa. (5) Evaluate; di sini adalah tahap evaluasi ketika hasil purwarupa digunakan oleh pengguna kemudian dilakukan analisa untuk perbaikan dan perkembangan lebih lanjut.

\section{HASIL DAN DISKUSI}

Seperti yang telah dijelaskan diatas, penelitian ini dilakukan berdasarkan metodologi Design Thinking. Tahapan pertama adalah Empathize, dilakukan dengan melakukan wawancara dengan calon pengguna yaitu mahasiswa dari kampus UPJ yang menggunakan kursi roda. Wawancara dilakukan melalui media Zoom pada tanggal 14 Oktober 2020 (Gambar 2).

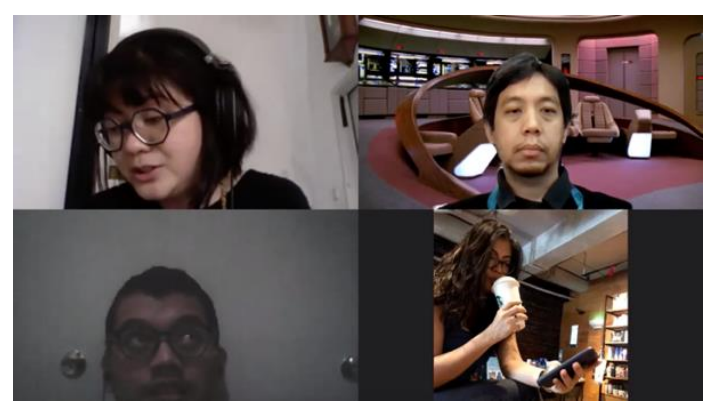

Gambar 2. Wawancara dengan calon pengguna menggunakan media daring Zoom 
Data yang didapatkan dari wawancara tersebut kemudian dianalisa dengan menggunakan Peta Empati versi Norman \& Nielsen (Gambar 3). Tujuannya adalah untuk identifikasi dan memenuhi kebutuhan yang diperlukan oleh pengguna produk.

Tahapan berikutnya adalah Define,merupakan analisa dari Peta Empati. Hasilnya dapat ditarik beberapa kesimpulan perihal kebutuhan calon pengguna, di antaranya adalah:

1. Narasumber tidak banyak mengalami masalah apabila dibantu oleh satu orang pendamping.

2. Narasumber akan mengalami masalah apabila melakukan semuanya seorang diri.

3. Kegiatan narasumber di dalam kelas adalah menyimak penjelasan materi serta melakukan sesi diskusi.

4. Terkadang narasumber melakukan presentasi untuk kebutuhan tugas kuliah.

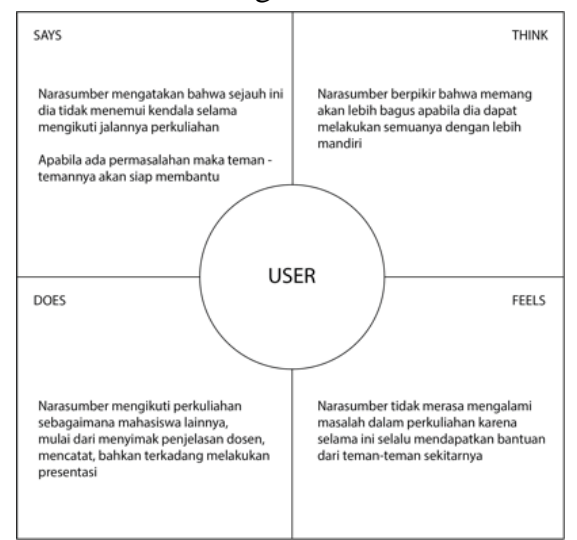

Gambar 3. Peta Studi Empati Norman \& Nielsen yang sudah di isi berdasarkan data dari hasil wawancara (Sumber gambar: Tim Penulis)

Tahap selanjutnya adalah Ideation, di mana dilakukan pembuatan sketsa desain dan brainstorming pengembangan konsep desain yang dapat mengakomodasi 4 poin kebutuhan di atas. Hasilnya yaitu berupa desain meja dengan nama meja DAYA, yang diambil dari kata berdaya. Harapannya adalah agar produk ini dapat membuat pengguna lebih berdaya dan mampu untuk beraktivitas dengan mandiri. Produk tersebut diharapkan dapat mengakomodasi kebutuhan mahasiswa disabilitas pengguna kursi roda di dalam kelas (Gambar 4).

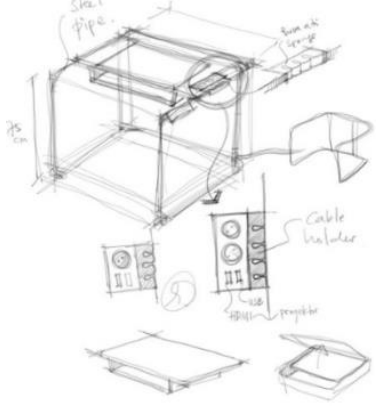

Gambar 4. Sketsa desain
Setelah melalui proses Ideation, kemudian dilanjutkan dengan proses pembuatan prototype atau purwarupa. Dengan tujuan untuk mendapatkan posisi dan bentuk yang ideal, maka selanjutnya dilakukan studi awal berupa pembuatan gambar 3 dimensi (Gambar 5). Hal ini untuk mendapatkan gambaran mengenai detail dimensi dan produk meja. Kemudian dilanjutkan dengan pembuatan studi dimensi ukuran 1:1 berupa mock up produk (Gambar 6).

Hasil dari mock up tersebut, selanjutnya diwujudkan dalam bentuk prototype atau purwarupa. Untuk saat ini, proses penyelesaian pembuatan prototip masih $60 \%$ dikarenakan sulitnya untuk menemukan workshop atau perajin yang mampu mengerjakan dalam waktu yang singkat. Kendala waktu pengerjaan yang singkat ini, menyebabkan biaya pembuatan prototype dengan biaya tinggi. Prototype dibuat sebanyak 2 unit. Selanjutnya kedua prototype tersebut akan ditempatkan di dua gedung Universitas Pembangunan Jaya.

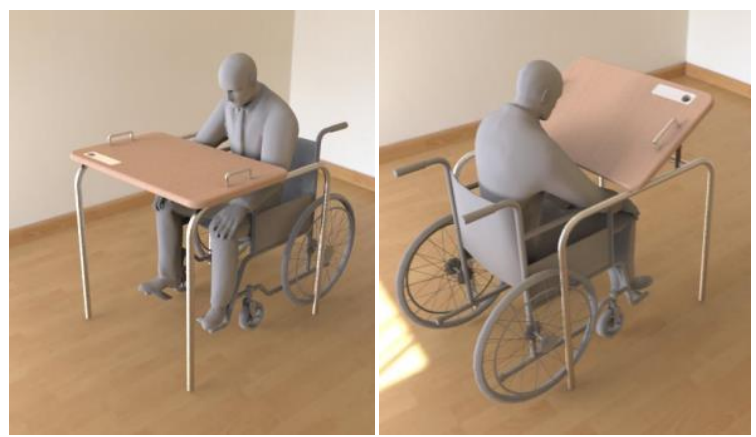

Gambar 5. Studi 3 dimensi

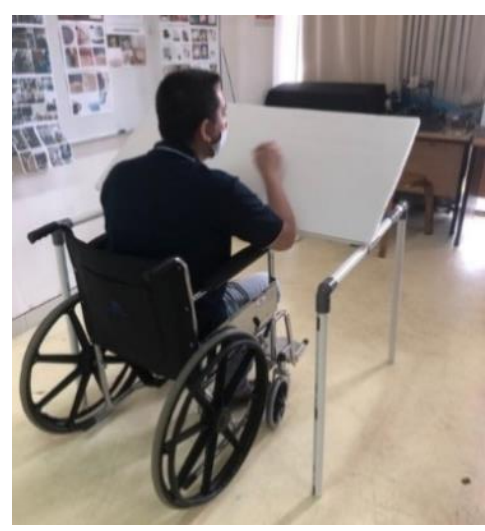

Gambar 6. Studi mock up 1:1

Desain awal dari prototype meja tersebut menggunakan pipa besi diameter $3 \mathrm{~cm}$ dengan teknik bending dan las. Namun dikarenakan keterbatasan waktu pengerjaan yang membuat banyak workshop besi menolak untuk mengerjakannya, maka dilakukan revisi desain yaitu struktur rangka meja menggunakan pipa kotak galvanis ukuran $4 \mathrm{~cm} \mathrm{x} 4 \mathrm{~cm}$ (Gambar 7). Perubahan ini, mempengaruhi hasil akhir tampilan visual dari produk. Selain itu, revisi desain yang dilakukan dapat mempersingkat proses pembuatan prototype produk (Gambar 8). 


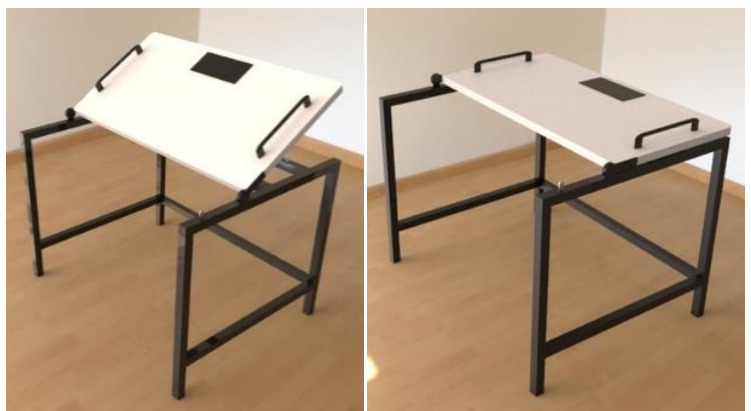

Gambar 7. Hasil revisi desain

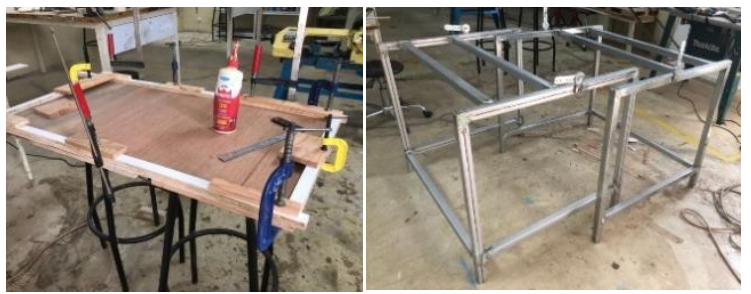

Gambar 8. Proses pembuatan prototip

Meja DAYA ini, didesain dengan alas yang dapat diatur sudut kemiringannya, proses penggunaannya dapat dilakukan dengan sangat mudah oleh pengguna kursi roda. Untuk memenuhi fungsi tersebut, diperlukan sistem engsel khusus agar kemiringannya dapat disesuaikan dengan kebutuhan penggunanya. Setelah melalui proses uji coba terhadap beberapa jenis engsel, diputuskan untuk memakai engsel yang digunakan untuk produk furnitur yaitu engsel sofa bed (Gambar 9). Engsel jenis ini dipilih dengan pertimbangan kemampuan untuk dapat menopang dan menahan beban yang berat.

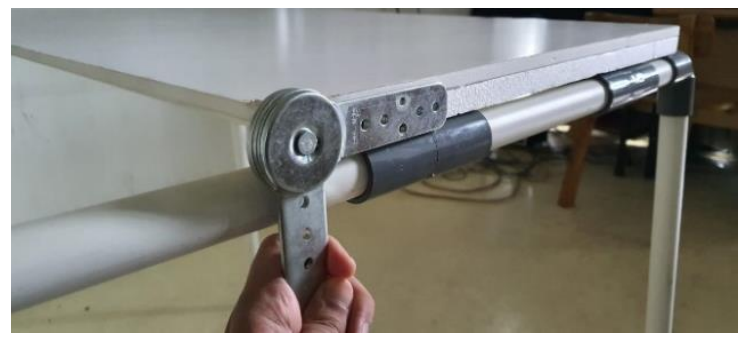

Gambar 9. Engsel meja

Tahap berikutnya adalah menganalisa pengalaman pengguna ketika akan mengakses sumber listrik. Pada desain awal, konektor sumber listrik ditempatkan pada alas meja. Selanjutnya dilakukan revisi desain agar pengguna tidak kesulitan dalam mengoperasikannya. Pada desain meja sebelumnya, ditemukan bahwa untuk mengakses konektor listrik, pengguna mengalami kesulitan dan penempatan kabel memerlukan jalur kabel khusus, terutama ketika papan meja diposisikan miring. Berdasarkan hal tersebut, pada prototype ke kedua, posisi konektor dipindahkan kebagian rangka meja sebelah kiri (Gambar 10).

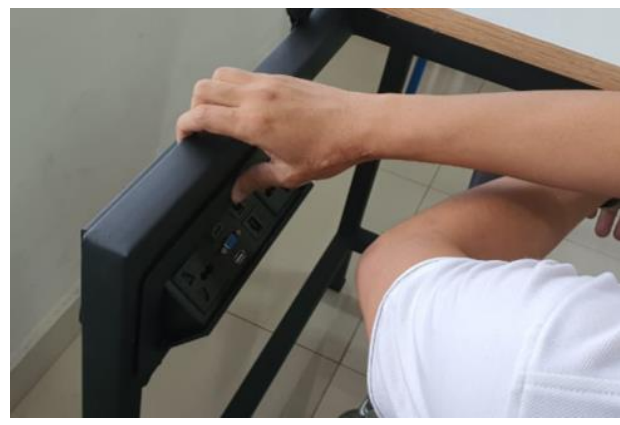

Gambar 10. Posisi konektor listrik

Hasil akhir prototype kemudian ditempatkan di ruang kelas perkuliahan, selanjutnya dilakukan pemasangan instalasi kabel yang menghubungkan ke sumber listrik dan alat proyektor. Setelah instalasi kabel selesai, tahap berikutnya yaitu melakukan uji coba untuk simulasi penggunaan meja DAYA (Gambar 11), Setelah itu melakukan proses penilaian dari keseluruhan proses penggunaan produk tersebut. Hasil dari penilaian ini akan menjadi bahan pertimbangan untuk pengembangan produk ke depannya.

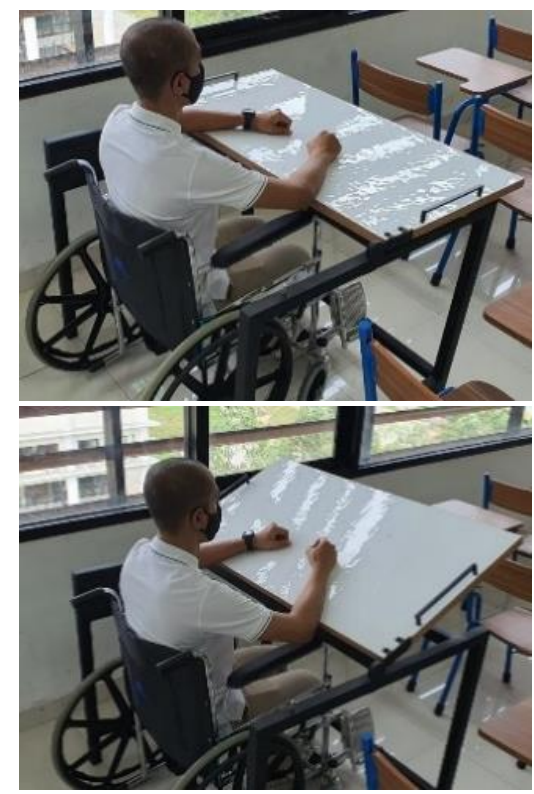

Gambar 11. Simulasi penggunaan meja

\section{KESIMPULAN}

Meja DAYA adalah sebuah produk fungsional yang bertujuan untuk mengakomodasi kebutuhan mahasiswa pengguna kursi roda agar dapat beraktivitas di ruang perkuliahan secara mandiri. Salah satu parameternya adalah, pada saat mahasiswa disabilitas pengguna kursi roda akan mengikuti perkuliahan dan menggunakan meja, mahasiswa tersebut dapat langsung menggunakannya tanpa harus berpindah kursi atau memindahkan kursi terlebih dahulu. Kemudahan dalam menggunakan 
fasilitas ini, secara langsung dapat menumbuhkan perasaan percaya diri dan merasa diri mereka tidak berbeda dengan mahasiswa lainnya yang tidak menggunakan kursi roda.

Kesimpulan lain yang didapatkan dari penelitian ini adalah pentingnya studi empati dan perilaku pengguna, terutama untuk produk dengan pengguna kaum penyandang disabilitas. Hal ini dikarenakan penerapan studi ergonomi saja tidak cukup, sebab studi ergonomi lebih cenderung kepada perspektif secara fisik saja, tetapi aspek kebiasaan pengguna sering kali luput dari perhatian.

Meja DAYA ini mengimplementasikan studi yang berkaitan dengan empati pemakainya, melalui beberapa fitur yang memang didesain berdasarkan kebutuhan dan kebiasaan penggunaan produk. Dari hasil analisa kebutuhan penggunaan produk, selanjutnya dibuat skala prioritas kebutuhan sebagai dasar untuk menetapkan batasan dan lingkup kebutuhan yang bisa di akomodasi oleh produk yang akan didesain.

Prototip dari meja DAYA ini telah ditempatkan di kelas perkuliahan dan akan digunakan ketika pertemuan tatap muka telah dijalankan. Penelitian ini akan berlanjut pada observasi penggunaan meja DAYA oleh pengguna agar dapat diketahui kekurangan dan potensi perbaikan.

\section{PENGAKUAN}

Artikel ini adalah salah satu hasil luaran dari penelitian Hibah Bantuan Dana Inovasi Pembelajaran dan Teknologi Bantu untuk Mahasiswa Berkebutuhan Khusus Perguruan Tinggi Tahun 2020.

\section{REFERENSI}

Syafi'ie, M. (2014). Pemenuhan Aksesibilitas Bagi Penyandang Disabilitas. INKLUSI, 1(2), 299-380.

World Health Organization (2011). World report on disability 2011.

Lutfiyah, K., Pribadi, S., Rosnarti, D. (2020). Fasilitas Dan Aksesibilitas Difabel Pada Bangunan Music Center Di Bsd, Tangerang. Prosiding Seminar Intelektual Muda \#4, pp.260-268.

Imrie, B. (2000). Responding to the Design Needs of Disabled People. Journal of Urban Design, 1(5), 199219.

Shinohara, K., Cynthia, L., Wobbrock, B. (2016). How Designing for People With and Without Disabilities Shapes Student Design Thinking. Proceedings of the 18th International ACM SIGACCESS Conference on Computers and Accessibility, pp.229-237.

Anoraga, P. (1998). Psikologi Kerja. Rineka Cipta. Jakarta. Indonesia.

Brown, T. (2008). Design Thinking. Harvard Business Review. June.

Gibbons, S. (2018). Empathy Mapping: The First Step of Design Thinking. Retrieved from: https://www.nngroup.com/articles/empathymapping/

Pemerintah Indonesia. (2009). Peraturan Menteri Pendidikan Nasional No. 70 Tahun 2009 Yang Mengatur Tentang Pendidikan Inklusif Bagi Peserta
Didik Yang Memiliki Kelainan dan Memiliki Potensi Kecerdasan dan/atau Bakat Istimewa.

Wignjosoebroto, S. (2007). Ergonomi Studi Gerak dan Waktu. Guna Widya. Yogyakarta. Indonesia. 